\title{
The Impact of Undergraduate Research on Academic Success
}

\begin{abstract}
This article assesses the accuracy of the assumption that undergraduate research leads to better student outcomes. In particular, it examines whether research involvement by undergraduates predicts subsequent academic success, as measured by grade point average (GPA). Consistent with predictions, results from a series of multiple regression analyses demonstrate that research involvement is associated with higher undergraduate GPA. This effect holds true even when controlling for numerous factors likely to affect both college GPA and the decision to become involved in research (e.g., high school GPA, the number of years in college, and parental college attendance). Additional analyses examine whether the timing of participation in research during a student's college career influences their GPA. Implications for staff and faculty who oversee and promote undergraduate research are discussed.
\end{abstract}

Keywords: assessment, student outcomes, student success, undergraduate research

\section{doi: $10.18833 /$ spur/1/3/8}

In the past quarter-century, many colleges and universities have begun to increase their emphasis on faculty research productivity. This is true even for predominantly undergraduate institutions (Kuh, Chen, and Laird 2007; Malachowski 2012). One often overlooked benefit of this increased attention to research is that undergraduate students have more opportunities than ever to be involved in faculty-mentored research activities. As such, faculty are increasingly encouraged to meaningfully incorporate undergraduate students into their research programs
(Boyer 1997). Indeed, when recruiting prospective students, colleges and universities may use the numerous research opportunities available to their students as a selling point. Presumably, increased emphasis on research and subsequent student involvement is beneficial for student outcomes-but, is this true?

Despite the general praise for undergraduate research, for the majority of the twentieth century, there was relatively little statistical evidence demonstrating the objective benefits of research involvement. As Spilich $(1997,57)$ historically noted, "The belief that research experience enhances the education of undergraduates is widespread but is based mostly on anecdotal evidence." Fortunately, over the past 20 years, there has been an effort to move beyond anecdotal evidence and more empirically assess the relationship between research involvement and student success.

In this vein, some researchers have focused on the relationship between undergraduate research involvement and graduate school admission. For example, Hathaway, Nagda, and Gregerman (2002) showed that students who engaged in undergraduate research were more likely to attend graduate school. This is consistent with the fact that graduate schools appear to value students with previous research experience and often recruit students who have been involved in research (Narayanan 1999). Although this is indeed a favorable result for undergraduate researchers, it is possible that this relationship exists only because universities serving graduate students fall prey to the same assumptions as their institutions serving primarily undergraduates-namely, the assumption that involvement in undergraduate research somehow indicates a more exceptional academic ability. 
Other researchers have attempted to assess the benefits of research involvement through surveys about the research experience. Simmons et al. (2016), for example, report the percentages of agreement by students and faculty on a variety of statements such as "[m]y participation in [research program] has led to more students doing research in classes..." Howitt and Wilson (2016; see also Wilson et al. 2015) examined the qualitative aspects of open-ended questions answered by student researchers in a reflection assignment. Bauer and Bennett (2003) examined how alumni recall and perceive their prior undergraduate research experience. In addition, Lopatto (2007) used an online survey to show gains in various skills after a research experience. Moreover, in recent years, there has been a renewed focus on creating reliable scales to measure student perceptions of research (Sams et al. 2015). Generally, these surveys have shown that students and faculty perceive the research experience to be very beneficial. A nationwide survey of several thousand undergraduate researchers revealed that the majority of respondents felt their confidence increased after doing the research and also believed that the research experience provided a better understanding of graduate school demands (Russell, Hancock, and McCullough 2007). Although these types of reflections about an individual's research experience are useful for assessing subjective perceptions of the benefits of the research involvement, they lack an objective standard by which to judge student success.

Given these issues, how, then, should student success be measured in relation to undergraduate research experience? Perhaps one of the most well-known objective measures of student success is grade point average (GPA). For decades and across numerous domains, researchers have used GPA as a measure of academic success (e.g., Oliphant and Alexander 1982; Werbel and Loomey 1994; Farsides and Woodfield 2003). This is done for many reasons. GPA is readily available for every student and provides a single quantitative number that sums up a student's ability across numerous academic domains. Aside from its ease of access and interpretation, GPA is also positively related to many outcome measures that, at face value, appear to be related to student success. For example, undergraduate GPA is predictive of postgraduation job success, graduate school admission, GRE scores, and graduate school GPA (Wise 1975; Dye and Reck 1989; Onasch 1994; Roth and Clarke 1998; Roth and Bobko 2000; Newton and Moore 2007; Newton et al. 2007). GPA is, of course, not a perfect measure of student success; several factors unrelated to academic success may affect a student's GPA, and GPA can be too coarse of a measure to reflect specific areas in which a student may be more or less successful. Nevertheless, examining the extent to which undergraduate research experience predicts GPA may be a useful step in assessing the benefits of undergraduate research.
Some prior studies have examined the relationship between undergraduate research involvement and college GPA, and their findings do indicate that undergraduates with research experience have a higher GPA (Russell et al. 2007; Schneider, Bickel, and Morrison-Shetlar 2015). However, those studies did not control for various factors that may explain that relationship. For example, students who had a high GPA in high school are very likely also to have a high GPA in college, and it is possible these same students may also be more inclined to seek out research experience once in college or be recruited by academics conducting research (e.g., Eagan et al. 2013). Thus, this research aimed to rule out such alternative explanations by performing statistical analyses that control for multiple factors relating to GPA and research experience.

This article assesses the effect of undergraduate research involvement on GPA at a small, private, predominantly undergraduate university in southern California. It was predicted that (1) undergraduates who participated in research would have a higher GPA than undergraduates who did not participate in research, and (2) this effect would hold true even when controlling for individual factors that may affect GPA and involvement in research. Finally, the researchers explored whether the timing of initial research involvement (earlier or later in the individual's college career) was a predictor of academic success, as measured by GPA.

\section{California Lutheran University's Undergraduate Research Program}

California Lutheran University is a small private university in Southern California. As might be expected from a predominantly undergraduate university, teaching and mentorship are at the heart of the institution's mission. Increasingly, and in line with other similar institutions (Kuh et al. 2007), faculty in all disciplines are expected to conduct publishable research. The institutional culture is such that there is a strong emphasis on involvement of undergraduates in faculty research.

When mentoring undergraduate researchers, faculty are encouraged to shape the specifics of the research experience in a way that fits the scholarship of their disciplines. Thus, the type of research experience can vary significantly from department to department and even within departments from one faculty member to another. As can be imagined, the skills learned by a student as part of a chemistry research project can be quite different from what another student learns as part of a psychology project. Moreover, mentorship models can vary substantially across the university; some faculty prefer to have large groups of students work together on research projects, whereas other faculty like to work one-on-one with individual students. Faculty also have various methods of student recruitment; for example, some will accept 
any student who has completed a prerequisite methods class, whereas others have a lengthy application process. Despite these differences, a central office-the Office of Undergraduate Research and Creative Scholarship (OURCS)_oversees undergraduate research at the university. This office helps to facilitate undergraduate research endeavors in numerous ways such as hosting research symposia, professional development workshops, and training sessions on various aspects of the research process. The OURCS is also responsible for managing lines of funding from privately donated research fellowships to provide faculty and students with summer research stipends and reimbursing students for supply costs and travel expenses to conferences where they presented their research. Students who receive funding from the OURCS are required to present their finished work at an annual on-campus event, and all summer research students are required to attend eight professional development workshops during their research period.

Beginning in the 2013-2014 academic school year, the university began systematically tracking undergraduate involvement in research in all disciplines across the entire university, throughout the year. This was accomplished by having students register for credits when conducting research during a given semester (fall, spring, or summer). Students were asked to register for research credits regardless of the type of research and whether or not funding was received for the research. Students could register for 0-3 units of research credit and could choose to receive a grade or take the credit as pass/fail. The only stipulation was that, to register for research credits, they needed to complete a contract of agreement similar to a syllabus, in which the details and objectives of the research project were outlined. Although the credit system is not a perfect method by which to track student participation in research (see Wolanin 2003), it can provide a record of research participation that, within the constraints of privacy laws, can be accessed and matched with other collected data on students (Schneider, Sullivan, and Collado 2016).

\section{Assessment and Outcomes}

To assess whether undergraduate research involvement predicts student GPA, two datasets were obtained from the Institutional Research office about students who, during their college career, had the opportunity to register for research credits. The first dataset included currently enrolled students with at least two semesters of data who began attending the university after the inception of the research tracking program (i.e., since fall 2013; $\mathrm{N}=$ 1,258). The second dataset included students who had an opportunity to gain research credits during their college career and graduated after the establishment of the research tracking program $(\mathrm{N}=791)$. For all students across both datasets, the following information was obtained: registration or nonregistration for research credit, gender, high school GPA, first-semester college GPA, parental college attendance, major division (e.g., social sciences, natural sciences), and Pell Grant status. The Pell Grant information was used as an indicator of family income (Dynarski 2002; Stedman 2003; Deming and Dynarski 2009).

In addition to this information, specifically for students in the first dataset (i.e., those currently enrolled), the following also was obtained: current cumulative GPA as of spring semester 2017, number of semesters enrolled in college, and the number of semesters of college attendance before enrollment in research credits). Similarly, for students in the second dataset (i.e., graduates), also obtained were the cumulative GPA at time of graduation; the total number of semesters spent in college; the number of semesters that research credits were available (most enrolled prior to the 2013-2014 academic year in which research credits became available); and finally, for enrollees in research credits, the point in their college career that they first became involved in research. The university's Institutional Review Board approved the study, procedures, and analyses.

\section{Currently Enrolled Students}

Of the 1,258 current undergraduate students at the university with at least two semesters of attendance who enrolled after the inception of the research credit tracking program, 4.8 percent $(n=61)$ have at some point during their college career registered for research credits. On average, the students who participated in undergraduate research had a higher current, cumulative college GPA $(M=3.58, S D=0.40)$ than students who never registered for research credits $(M=3.27, S D=0.45)$, $t(1256)=5.43, p<0.0001$. This finding is consistent with previous literature demonstrating a higher GPA among undergraduates involved in research (e.g., Schneider et al. 2015). However, there are many problems with this analysis-namely, it does not control for other factors likely to affect GPA and participation in research.

To more accurately assess the independent contribution of undergraduate research involvement on GPA, a multiple linear regression was run in which current college GPA was predicted from prior research involvement while controlling for high school GPA, the number of semesters in college, gender, first-generation college student status, major division (dummy coded), first-semester college GPA, and Pell Grant status. Involvement in research was still a significant predictor of cumulative GPA, $\beta=$ $0.050, p=0.005$, even while controlling for numerous other factors (see Table 1). Thus, the effect of research involvement on GPA is not solely attributable to these other factors.

Additionally, to further assess whether research experience affected a change in GPA across time, a matching analysis was performed. Propensity score matching has been 
TABLE 1. Multiple Linear Regression for Currently Enrolled Students on Cumulative GPA

\begin{tabular}{|c|c|c|c|c|c|}
\hline Variables & B & SE B & $\beta$ & $t$ & $p$ \\
\hline Pell Grant status & -0.028 & 0.018 & -0.029 & -1.527 & 0.127 \\
\hline High school cumulative GPA & 0.262 & 0.021 & 0.239 & 12.189 & $<0.001$ \\
\hline Semesters in college & 0.010 & 0.005 & 0.036 & 2.087 & 0.037 \\
\hline Gender & -0.026 & 0.017 & -0.028 & -1.517 & 0.130 \\
\hline Parental college attendance & -0.036 & 0.019 & -0.035 & -1.877 & 0.061 \\
\hline First-semester college GPA & 0.565 & 0.017 & 0.634 & 32.348 & $<0.001$ \\
\hline \multicolumn{6}{|l|}{ Major division } \\
\hline D1 (OT versus NS) & 0.082 & 0.024 & 0.067 & 3.457 & 0.001 \\
\hline D2 (BS versus NS) & 0.052 & 0.024 & 0.042 & 2.156 & 0.031 \\
\hline D3 (IES versus NS) & 0.204 & 0.043 & 0.085 & 4.761 & $<0.001$ \\
\hline D4 (HM versus NS) & 0.067 & 0.046 & 0.026 & 1.456 & 0.146 \\
\hline D5 (CA versus NS) & 0.143 & 0.034 & 0.077 & 4.178 & $<0.001$ \\
\hline D6 (SS versus NS) & 0.121 & 0.021 & 0.112 & 5.657 & $<0.001$ \\
\hline Participation in directed research & 0.104 & 0.037 & 0.050 & 2.840 & 0.005 \\
\hline Intercept & 0.366 & 0.850 & & & \\
\hline
\end{tabular}

Note: Adjusted R-squared for model $=0.642$

There was no multicollinearity among predictors, all VIFs $<2.0$.

Division Codes: OT = Other/Undeclared, BS = Business, IES = Interdisciplinary Educational Studies, HM = Humanities, CA = Creative Arts, $\mathrm{SS}=$ Social Sciences, NS = Natural Sciences

used successfully in several fields to test for causative effects in observational designs with nonrandom assignment (e.g., Eagan et al. 2013; Morgan and Harding 2006; Stuart 2010). In the analysis here, propensity scores were generated via a logistic regression in which research participation was predicted from all other predictor variables in the original model (i.e., high school GPA, the number of semesters in college, gender, first-generation college student status, major division, first-semester college GPA, and Pell Grant status). A subset of 61 nonresearchers was matched to the sample of 61 researchers using nearestneighbor propensity score matching. Subsequent analyses demonstrated that the matching algorithm was successful, as indicated by the fact that there was no significant difference between researchers and the matched nonresearcher group in any of the predictors used to create the matching, all $p$ 's $>0.25$ (see Table 2 for match comparisons).

A mixed-model ANOVA was run on this matched data to test for differences between current cumulative GPA and first-semester GPA (within subjects) for researchers versus nonresearchers (between subjects). Overall, there was a trend for current GPA $(M=3.54, S D=0.37)$ to be slightly lower compared to first-semester GPA $(M=3.58, S D=$ $0.37), F(1,120)=3.41, p=0.067$. However, there was a marginally significant interaction between this change in GPA and research involvement, $F(1,120)=3.15, p=0.078$.
Follow-up analyses showed that involvement in undergraduate research seemed to have a protective effect on the typical decrease in GPA over time. For students who were not involved in research, current cumulative GPA was lower $(M=3.50, S D=0.34)$ than first-semester GPA $(M=3.58, S D=0.34), t(60)=2.37, p=0.021$. In contrast, for students who were involved in research, there was no significant difference between first-semester GPA $(M=$ $3.59, S D=0.40)$ and current cumulative GPA $(M=3.58$, $S D=0.40), t(60)=0.06, p=0.96$.

\section{Graduates}

A set of analyses similar to that applied to currently enrolled students was carried out for the students who graduated since the inception of the research credits tracking program, using the students' cumulative bachelor's degree GPA as a dependent variable. Students who had at least one semester of undergraduate research $(n=89$, 11.3 percent) had a higher cumulative bachelor's GPA ( $n$ $=89, M=3.54, S D=0.33$ ) than students who had never conducted undergraduate research $(n=702, M=3.34$, $S D=0.38), t(120.7)=5.47, p<0.0001$ (Levene's Test for Equality of Variances was significant, so an independent samples $t$-test with equal variances not assumed was computed). Again, since many factors can affect GPA, a multiple linear regression was run to test for the effect of undergraduate research on cumulative GPA at graduation, 
TABLE 2. Characteristics of Matched Samples for Currently Enrolled Students

\begin{tabular}{|c|c|c|c|}
\hline Variables & Researcher & Nonresearcher & $p$ Value \\
\hline High school cumulative GPA-mean (SD) & $3.86(0.41)$ & $3.89(0.37)$ & 0.621 \\
\hline First-semester college GPA—mean (SD) & $3.59(0.40)$ & $3.58(0.34)$ & 0.938 \\
\hline Semesters in college-mean (SD) & $6.75(1.16)$ & $6.85(1.39)$ & 0.672 \\
\hline \multicolumn{4}{|l|}{ Gender- $n(\%)$} \\
\hline Female & $38(62 \%)$ & $42(69 \%)$ & 0.454 \\
\hline Male & $23(38 \%)$ & $19(31 \%)$ & \\
\hline \multicolumn{4}{|l|}{ Parental college attendance $-n(\%)$} \\
\hline First generation & $19(31 \%)$ & $14(23 \%)$ & 0.318 \\
\hline Not first generation & $42(69 \%)$ & $47(78 \%)$ & \\
\hline \multicolumn{4}{|l|}{ Parental income $-n(\%)$} \\
\hline Received Pell Grant & $28(46 \%)$ & $22(36 \%)$ & 0.277 \\
\hline Did not receive Pell Grant & $33(54 \%)$ & $39(64 \%)$ & \\
\hline \multicolumn{4}{|l|}{ Division- $n(\%)$} \\
\hline Social Sciences & $17(28 \%)$ & $17(28 \%)$ & 0.981 \\
\hline Natural Sciences & $36(59 \%)$ & $38(62 \%)$ & \\
\hline IES & $2(3 \%)$ & $2(3 \%)$ & \\
\hline Humanities & $2(3 \%)$ & $1(2 \%)$ & \\
\hline Creative Arts & $0(0 \%)$ & $0(0 \%)$ & \\
\hline Business & $2(3 \%)$ & $2(3 \%)$ & \\
\hline Other & $2(3 \%)$ & $1(2 \%)$ & \\
\hline
\end{tabular}

Note: Percentages may not add to 100 due to rounding.

$p$-values for continuous variables are the result of independent $t$-tests, whereas $p$-values for categorical variables are the results of chi-square tests of independence.

controlling for the number of semesters completed for graduation, the number of semesters in which undergraduate research was available, gender, high school cumulative GPA, first-generation college student status, major division (dummy coded), first-semester college GPA, and Pell Grant status. Involvement in undergraduate research was a significant predictor of GPA at graduation, $\beta=0.101, p<0.001$ (see Table 3). In other words, graduation GPA was statistically higher among students involved in undergraduate research as compared to other students, while controlling for numerous other factors that can affect GPA.

A matching analysis was also conducted for graduates to assess the effect of research experience on the change in GPA across time. Propensity scores were generated via a logistic regression in which research participation was predicted from all other predictor variables in the original model (i.e., the number of semesters completed for graduation, the number of semesters in which undergraduate research was available, gender, high school cumulative
GPA, first-generation college student status, major division, first-semester college GPA, and Pell Grant status) and matched using the nearest-neighbor method. The resulting subset of data included 178 students, 89 researchers, and 89 nonresearchers, statistically similar across all baseline characteristics, all $p$ 's $>0.50$ (see Table 4 for match comparisons).

A mixed-model ANOVA was run on this matched data to test for differences between GPA at graduation and first semester GPA (within subjects) among researchers versus nonresearchers (between subjects). Overall, GPA at graduation $(M=3.47, S D=0.34)$ was higher than first-semester GPA $(M=3.40, S D=0.47), F(1,176)=$ $8.30, p=0.004$. There was also a significant interaction between this change in GPA and student research involvement, $F(1,176)=4.51, p=0.035$. For student researchers, their GPAs at graduation $(M=3.54, S D=0.33)$ were higher than their first-semester GPAs $(M=3.42, S D=.52)$, $t(88)=3.28, p<0.001$. However, nonresearch students did not show a significant change in GPA across time 
TABLE 3. Multiple Linear Regression for Graduated Students on Cumulative GPA

\begin{tabular}{|c|c|c|c|c|c|}
\hline Variables & B & SE B & $B$ & $t$ & $p$ \\
\hline Pell Grant status & -0.057 & 0.020 & -0.067 & -2.789 & 0.005 \\
\hline High school cumulative GPA & 0.245 & 0.026 & 0.249 & 9.294 & $<0.001$ \\
\hline Gender & 0.010 & 0.019 & 0.013 & 0.551 & 0.582 \\
\hline Parental college attendance & -0.001 & 0.021 & -0.001 & -0.051 & 0.959 \\
\hline Time to degree & -0.084 & 0.021 & -0.095 & -3.978 & $<0.001$ \\
\hline Semesters of directed research possible & 0.000 & 0.005 & 0.001 & 0.026 & 0.979 \\
\hline First-semester GPA & 0.438 & 0.020 & 0.587 & 22.278 & $<0.001$ \\
\hline \multicolumn{6}{|l|}{ Major division } \\
\hline D1 (OT versus NS) & 0.127 & 0.023 & 0.160 & 5.629 & $<0.001$ \\
\hline D2 (BS versus NS) & 0.052 & 0.026 & 0.053 & 1.961 & 0.050 \\
\hline D3 (IES versus NS) & 0.072 & 0.171 & 0.010 & 0.423 & 0.672 \\
\hline D4 (HM versus NS) & 0.101 & 0.047 & 0.052 & 2.148 & 0.032 \\
\hline D5 (CA versus NS) & 0.098 & 0.040 & 0.059 & 2.432 & 0.015 \\
\hline D6 (SS versus NS) & 0.201 & 0.039 & 0.125 & 5.160 & $<0.001$ \\
\hline Participation in directed research & 0.121 & 0.029 & 0.101 & 4.243 & $<0.001$ \\
\hline Intercept & 1.258 & 0.140 & & & \\
\hline
\end{tabular}

Note: Adjusted R-squared for model $=0.605$

There was no multicollinearity among predictors, all VIFs $<2.0$

Division Codes: OT = Other/Undeclared, BS = Business, IES = Interdisciplinary Educational Studies, HM = Humanities, CA = Creative Arts,

$\mathrm{SS}=$ Social Sciences, NS $=$ Natural Sciences

(first-semester GPA $M=3.39, S D=0.42$; graduation GPA $M=3.40, S D=0.34 ; t(88)=0.59, p=0.56)$.

\section{Early Involvement in Research}

To explore the idea that the timing of research involvement has an effect on academic success, a set of analyses was conducted that focused solely on students who had participated in undergraduate research at some point in their college career. For each dataset, multiple linear regression analysis was performed, predicting GPA from the timing of the initial involvement in research while controlling for other factors that also affect GPA.

\section{Currently Enrolled Students}

For currently enrolled students who were enrolled in undergraduate research credits, the number of semesters before starting research (more semesters = later research experience) was a significant predictor of cumulative GPA, $\beta=-.23, p=0.028$ (see Table 5), while controlling for the number of semesters in college, gender, high school GPA, first-generation college student status, first-semester college GPA, major division, and Pell Grant status. That is, students who engaged in undergraduate research opportunities early in their college career had higher current GPAs than those who began their research later in their studies.

\section{Graduates}

For students who were enrolled in undergraduate research credits at some point in their undergraduate career and have graduated, the number of semesters between first enrolling in undergraduate research and graduating (additional semesters $=$ earlier research experience) was not a significant predictor of GPA at graduation, $\beta=-.07$, $p=0.46$ (see Table 6), while controlling for the number of semesters the research credits were available, the number of semesters completed for graduation, gender, high school GPA, first-generation college student status, major division, first-semester GPA, and Pell Grant status. Thus, for graduates, earlier research involvement did not predict GPA at graduation. The apparent inconsistency between graduates and currently enrolled students in the effect of timing of research involvement on GPA is discussed below.

\section{Conclusion}

Overall, these results show a clear indication that participation in research is associated with increased student success, as measured by GPA. This is true for both current students and graduated students, and is consistent with previous studies which found a similar positive association between involvement in undergraduate research and GPA 
TABLE 4. Characteristics of Matched Samples for Graduated Students

\begin{tabular}{|c|c|c|c|}
\hline Variables & Researcher & Nonresearcher & $p$ Value \\
\hline High school cumulative GPA—mean (SD) & $3.89(0.36)$ & $3.88(0.30)$ & 0.813 \\
\hline First-semester college GPA—mean (SD) & $3.42(0.52)$ & $3.39(0.42)$ & 0.639 \\
\hline Semesters of research possible-mean (SD & $6.08(1.53)$ & $6.02(1.64)$ & 0.795 \\
\hline Time to degree - mean (SD) & $3.77(0.33)$ & $3.80(0.39)$ & 0.537 \\
\hline \multicolumn{4}{|l|}{ Gender- $n(\%)$} \\
\hline Female & $59(66 \%)$ & $60(67 \%)$ & 0.875 \\
\hline Male & $30(34 \%)$ & $29(33 \%)$ & \\
\hline \multicolumn{4}{|l|}{ Parental college attendance $-n(\%)$} \\
\hline First generation & $28(31 \%)$ & $30(34 \%)$ & 0.749 \\
\hline Not first generation & $61(69 \%)$ & $59(66 \%)$ & \\
\hline \multicolumn{4}{|l|}{ Parental income- $n(\%)$} \\
\hline Received Pell Grant & $23(26 \%)$ & $27(30 \%)$ & 0.511 \\
\hline Did not receive Pell Grant & $66(74 \%)$ & $62(70 \%)$ & \\
\hline \multicolumn{4}{|l|}{ Division- $n(\%)$} \\
\hline Social Sciences & $13(15 \%)$ & $19(21 \%)$ & 0.686 \\
\hline Natural Sciences & $57(64 \%)$ & $48(54 \%)$ & \\
\hline IES & $1(1 \%)$ & $0(0 \%)$ & \\
\hline Humanities & $1(1 \%)$ & $1(1 \%)$ & \\
\hline Creative Arts & $1(1 \%)$ & $2(2 \%)$ & \\
\hline Business & $2(2 \%)$ & $4(5 \%)$ & \\
\hline Other & $14(16 \%)$ & $15(17 \%)$ & \\
\hline
\end{tabular}

Note: Percentages may not add to 100 due to rounding.

$p$-values for continuous variables are the result of independent $t$-tests, whereas $p$-values for categorical variables are the results of chi-square tests of independence.

(e.g., Russell et al. 2007; Schneider et al. 2015). Importantly, this set of results adds to previous findings in that it controls for factors that can be highly predictive of both college GPA and involvement in undergraduate research. Thus, the current findings cannot easily be explained by other factors that predispose a student to be both involved in research and be successful in college. Ruling out such confounds is a critical step in demonstrating a direct role of research involvement in student success.

Higher education institutions place a large emphasis on involving students in research. The current findings suggest that such an emphasis is academically beneficial for students. In addition, some faculty and staff advocate that students should become involved in research early in their academic career (e.g., Ishiyama 2002). The results reported here are somewhat ambiguous in regard to this latter proposition. In this study, earlier involvement in research was associated with higher cumulative GPA among currently enrolled students but not for graduates.
One possible reason for this discrepancy is that the research credit tracking system has been in place for the entirety of the currently enrolled students' college years; this was not the case for graduates. Consequently, the earliest involvement in research of enrolled students was more likely to be captured accurately. However, many of the graduates actually may have begun participation in research before the tracking system was implemented. Given the uncertainty in the exact timing of initial research involvement for graduates, analyses examining the effects of this variable are likely to be less sensitive. In sum, based on the current results, whether or not earlier involvement in undergraduate research is beneficial is not entirely clear, but it is a promising direction for future research.

Although the current findings are encouraging, it is important to note a few caveats that may limit the generalizability of these results. First, California Lutheran University places a great deal of emphasis on teaching and mentorship, as represented by small class sizes and 
The Impact of Undergraduate Research

TABLE 5. Multiple Linear Regression for Currently Enrolled Research Students on Cumulative GPA, Including Timing of Research Experience

\begin{tabular}{|c|c|c|c|c|c|}
\hline Variables & B & SE B & $\beta$ & $t$ & $p$ \\
\hline Pell Grant status & -0.070 & 0.075 & -0.088 & -0.939 & 0.352 \\
\hline High school cumulative GPA & 0.156 & 0.084 & 0.161 & 1.865 & 0.068 \\
\hline Semesters in college & 0.048 & 0.032 & 0.139 & 1.498 & 0.141 \\
\hline Gender & -0.045 & 0.072 & -0.055 & -0.628 & 0.533 \\
\hline Parental college attendance & 0.051 & 0.085 & 0.059 & 0.594 & 0.555 \\
\hline First-semester college GPA & 0.670 & 0.091 & 0.672 & 7.362 & $<0.001$ \\
\hline \multicolumn{6}{|l|}{ Major division } \\
\hline D1 (OT versus NS) & 0.172 & 0.177 & 0.077 & 0.972 & 0.336 \\
\hline D2 (BS versus NS) & 0.072 & 0.166 & 0.032 & 0.436 & 0.665 \\
\hline D3 (IES versus NS) & -0.029 & 0.168 & 0.013 & 0.175 & 0.862 \\
\hline D4 (HM versus NS) & 0.232 & 0.164 & 0.104 & 1.414 & 0.164 \\
\hline D6 (SS versus NS) & 0.091 & 0.076 & 0.103 & 1.204 & 0.235 \\
\hline $\begin{array}{l}\text { Semesters before individual started } \\
\text { directed research }\end{array}$ & & 0.021 & -0.228 & -2.269 & 0.028 \\
\hline Intercept & & 0.383 & & & \\
\hline
\end{tabular}

Note: Adjusted R-squared for model $=0.696$

There was no multicollinearity among predictors, all VIFs $<2.0$

Division Codes: OT = Other/Undeclared, BS = Business, IES = Interdisciplinary Educational Studies, HM = Humanities, SS = Social Sciences,

NS = Natural Sciences. D5 (CA versus NS) was removed from the model, as there were no student researchers from the Creative Arts division.

TABLE 6. Multiple Linear Regression for Graduated Research Students on Cumulative GPA, Including Timing of Research Experience

\begin{tabular}{|c|c|c|c|c|c|}
\hline Variables & B & SE B & $\beta$ & $t$ & $p$ \\
\hline Pell Grant status & 0.051 & 0.069 & 0.068 & 0.729 & 0.468 \\
\hline High school cumulative GPA & 0.058 & 0.079 & 0.064 & 0.730 & 0.467 \\
\hline Gender & -0.002 & 0.060 & -0.003 & -0.039 & 0.969 \\
\hline Parental college attendance & -0.081 & 0.069 & -0.116 & -1.180 & 0.242 \\
\hline Semesters of directed research possible & -0.006 & 0.020 & -0.028 & -0.300 & 0.765 \\
\hline First-semester college GPA & 0.490 & 0.065 & 0.776 & 7.539 & $<0.001$ \\
\hline Time to degree & 0.051 & 0.086 & 0.053 & 0.598 & 0.551 \\
\hline \multicolumn{6}{|l|}{ Major division } \\
\hline D1 (OT versus NS) & 0.094 & 0.065 & 0.132 & 1.433 & 0.156 \\
\hline D2 (BS versus NS) & 0.114 & 0.242 & 0.037 & 0.471 & 0.639 \\
\hline D3 (IES versus NS) & -0.190 & 0.246 & -0.062 & -0.770 & 0.443 \\
\hline D5 (CA versus NS) & 0.100 & 0.145 & 0.056 & 0.685 & 0.495 \\
\hline D6 (SS versus NS) & 0.112 & 0.255 & 0.037 & 0.442 & 0.660 \\
\hline $\begin{array}{l}\text { Semesters before graduating of } \\
\text { participant in directed research }\end{array}$ & -0.015 & 0.020 & -0.072 & -0.740 & 0.461 \\
\hline Intercept & 1.519 & 0.514 & & & \\
\hline
\end{tabular}

Note: Adjusted R-squared for model $=0.498$

There was no multicollinearity among predictors, all VIFs $<2.0$.

Division Codes: OT = Other/Undeclared, BS = Business, IES = Interdisciplinary Educational Studies, HM = Humanities, SS = Social Sciences,

NS = Natural Sciences. D4 (HM versus NS) was removed from the model, as there were no student researchers from the Humanities division.

26 Scholarship and Practice of Undergraduate Research 
close personal attention to mentees. Most undergraduate research students at the university work directly with a faculty mentor, in contrast to other universities where undergraduates may work more directly with graduate students and postdoctoral scholars. Thus, it is difficult to ascertain if the results in this article can generalize to institutions where research by faculty is hierarchicalfaculty supervise graduate students who then supervise undergraduate students. Second, a relatively low percentage of students enrolled in research credits. Again, this may be a reflection of faculty working with only a few students at a time so that a close mentorship structure is provided for the student. Alternatively, it is possible that the low percentage of research students reflects limitations in the research tracking program itself, which does not include students who volunteer for research projects but do not register for research credit (Wolanin 2003). However, if this proposition is true, it would only suggest that the current results are a conservative estimate of the benefits of undergraduate research on GPA and that a full enrollment by undergraduate researchers would produce effects even larger than those noted here. Third, it is important to note that students have the option of taking 0-3 credits as graded or pass/fail. The datasets used in this study did not include the number of credits or the grades earned by the student (if any) for the research units. Consequently, it is possible that this could have positively affected cumulative GPA; however, any such effect would likely be minimal given the vast amount of credits from other classes that are factored into calculating cumulative GPA.

Given these limitations, it is necessary for researchers to continue to assess the benefits of undergraduate research experiences. For example, similar analyses using data from large, research-oriented universities are needed to generalize these results to all undergraduate researchers. Additionally, it would be informative to explore other objective measures of student success such as salary after graduation and other career outcomes. It is also possible that there are some positive outcomes of undergraduate research that are mediated by GPA. For example, is the positive relationship between undergraduate research experience and acceptance to graduate school partially explained by the increased GPA among undergraduate researchers? Finally, it would be interesting to explore possible differences in outcomes between students that volunteer for research experiences and those who enroll in research credits. Answering such questions is necessary if the benefits of an undergraduate research experience are to continue to be promoted.

Undergraduate research experiences have become a focal point of many universities. There appears to be a good reason for this. Undergraduate research facilitates the development of important skills such as critical thinking and the ability to work with teammates (e.g., Lopatto 2007). By demonstrating that student researchers have higher GPAs than their counterparts, the current analyses provide the next step in establishing the benefits of the research experience. Malachowski $(2012,8)$ notes, "as the devotion to research continues to increase among faculty, I believe it is time to step back and ask fundamental questions about what kind of impact this new priority is having on undergraduate students and student learning." These findings are an important answer to the call for documentation of academic success among student researchers. Continuing to examine the numerous possible outcomes of student research, both subjective and objective, can provide a fuller understanding of the wide-ranging benefits of undergraduate research involvement.

\section{References}

Bauer, Karen W., and Joan S. Bennett. 2003. "Alumni Perceptions Used to Assess Undergraduate Research Experience.” Journal of Higher Education 74: 210-230. doi: 10.1353/jhe.2003.0011

Boyer, Ernest L. 1997. Scholarship Reconsidered: Priorities of the Professoriate. San Francisco: Jossey-Bass.

Deming, David, and Susan Dynarski. 2009. "Into College, Out of Poverty? Policies to Increase the Postsecondary Attainment of the Poor" (September). NBER Working Paper. doi:10.3386/ w15387

Dye, David A., and Martin Reck. 1989. "College Grade Point Average as a Predictor of Adult Success: A Reply." Public Personnel Management 18: 235-241. doi: 10.1177/00910 2608901800210

Dynarski, Susan. 2002. "The Behavioral and Distributional Implications of Aid for College." American Economic Review 92: 279-285. doi: 10.1257/000282802320189401

Eagan, M. Kevin, Jr., Sylvia Hurtado, Mitchell J. Chang, Gina A. Garcia, Felisha A. Herrera, and Juan C. Garibay. 2013. "Making a Difference in Science Education: The Impact of Undergraduate Research Programs." American Educational Research Journal 50: 683-713. doi: 10.3102/0002831213482038

Farsides, Tom, and Ruth Woodfield. 2003. "Individual Differences and Undergraduate Academic Success: The Roles of Personality, Intelligence, and Application." Personality and Individual Differences 34: 1225-1243. doi: 10.1016/s01918869(02)00111-3

Hathaway, Russel S., Biren A. Nagda, and Sandra R. Gregerman. 2002. "The Relationship of Undergraduate Research Participation to Graduate and Professional Education Pursuit: An Empirical Study." Journal of College Student Development 43: 614-631.

Howitt, Susan, and Anna Wilson. 2016. "Scaffolded Reflection as a Tool for Surfacing Complex Learning in Undergraduate Research Projects." CUR Quarterly 36(4): 33-38. doi: 10.18833/ curq/36/4/8

Ishiyama, John. 2002. "Does Early Participation in Undergraduate Research Benefit Social Science and Humanities Students?" College Student Journal 36: 381-387. 
Kuh, George D., Daniel Chen, and Thomas F. Nelson Laird. 2007. "Why Teacher-Scholars Matter: Some Insights from FSSE and NSSE." Liberal Education 93(4): 40. Washington, DC: Association of American Colleges \& Universities.

Lopatto, David. 2007. "Undergraduate Research Experiences Support Science Career Decisions and Active Learning." CBE-Life Sciences Education 6: 297-306. doi: 10.1187/ cbe.07-06-0039

Malachowski, Mitchell R. 2012. "Living in Parallel Universes: The Great Faculty Divide between Product-Oriented and Processed-Oriented Scholarship." In Faculty Support and Undergraduate Research: Innovations in Faculty Role Definition, Workload, and Reward, ed. Nancy H. Hensel and Elizabeth L. Paul, 7-18. Washington, DC: Council on Undergraduate Research.

Morgan, Stephen L., and David J. Harding. 2006. "Matching Estimators of Causal Effects: Prospects and Pitfalls in Theory and Practice." Sociological Methods \& Research 35: 3-60. doi: $10.1177 / 0049124106289164$

Narayanan, Ram M. 1999. "Use of Objective-Based Undergraduate Research Project Experience as a Graduate Student Recruitment Tool." Journal of Engineering Education 88: 361-365. doi: 10.1002/j.2168-9830.1999.tb00458.x

Newton, Sarah E., and Gary Moore. 2007. "Undergraduate Grade Point Average and Graduate Record Examination Scores: The Experience of One Graduate Nursing Program." Nursing Education Perspectives 28: 327-331.

Newton, Sarah E., Laureen H. Smith, Gary Moore, and Morris Magnan. 2007. "Predicting Early Academic Achievement in a Baccalaureate Nursing Program." Journal of Professional Nursing 23: 144-149. doi: 10.1016/j.profnurs.2006.07.001

Oliphant, Van N., and Elmore R. Alexander. 1982. "Reactions to Resumes as a Function of Resume Determinateness, Applicant Characteristics, and Sex of Raters." Personnel Psychology 35: 829-842. doi: 10.1111/j.1744-6570.1982.tb02225.x

Onasch, Christine. 1994. "Undergraduate Grade Point Average and Graduate Record Exam Scores as Predictors of Length of Enrollment in Completing a Master of Science Degree." ERIC Number: ED375739. http://eric.ed.gov/?id=ED375739

Roth, Philip L., and Philip Bobko. 2000. "College Grade Point Average as a Personnel Selection Device: Ethnic Group Differences and Potential Adverse Impact." Journal of Applied Psychology 85: 399-406. doi: 10.1037/0021-9010.85.3.399

Roth, Philip L., and Richard L. Clarke. 1998. "Meta-Analyzing the Relation between Grades and Salary." Journal of Vocational Behavior 53: 386-400. doi: 10.1006/jvbe.1997.1621

Russell, Susan H., Mary P. Hancock, and James McCullough. 2007. "Benefits of Undergraduate Research Experiences." Science 316: 548-549.

Sams, Doreen, Robin Lewis, Rebecca McMullen, Larry Bacnik, Jennifer Hammack, Rosalie Richards, and Caitlin Powell. 2015. "Measuring Self-Efficacy and Scientific Literacy across Disciplines at Value-Added Outcomes of Undergraduate Research Mentoring: Scale Development." CUR Quarterly 35(3): 23-30.

28 Scholarship and Practice of Undergraduate Research
Schneider, Kimberly R., Amelia Bickel, and Alison Morrison-Shetlar. 2015. "Planning and Implementing a Comprehensive Student-Centered Research Program for First-Year STEM Undergraduates." Journal of College Science Teaching 44(3): 37-43. doi: 10.2505/4/jcst15_044_03_37

Schneider, Kimberly R., Linda Sullivan, and Evangeline Collado. 2016. "A Centralized Undergraduate Research Database: Collaboration between Institutional Research and Universitywide Research Programs." CUR Quarterly 36(4):19-25. doi: $10.18833 /$ curq/36/4/6

Simmons, Jeffrey A., Laurel J. Anderson, David R. Bowne, Jerald J. Dosch, Tracy B. Gartner, Marth F. Hoopes, Karen Kuers, Erin S. Lindquist, Timothy S. McCay, Bob R. Pohland, Carolyn L. Thomas, and Kathleen L. Shea. 2016. "Collaborative Research Networks Provide Unique Opportunities for Faculty and Student Researchers." CUR Quarterly 36(4): 12-18. doi: 10.18833/ curq/36/4/4

Spilich, George. 1997. "Does Undergraduate Research Pay Off?" CUR Quarterly 18(2): 57-59.

Stedman, James B. 2003. Federal Pell Grant Program of the Higher Education Act: Background and Reauthorization. Washington, DC: Congressional Research Service.

Stuart, Elizabeth A. 2010. "Matching Methods for Causal Inference: A Review and a Look Forward." Statistical Science: A Review Journal of the Institute of Mathematical Statistics 25: 1-21. doi: 10.1214/09-sts313

Werbel, James D., and Steven Looney. 1994. "The Use of Selection Criteria for Campus Interviews." International Journal of Selection and Assessment 2(1): 28-36. doi: 10.1111/j.14682389.1994.tb00126.x

Wilson, Anna N., Susan M. Howitt, Denise M. Higgins, and Pamela J. Roberts. 2015. "Making Critical Thinking Visible in Undergraduates' Experiences of Scientific Research." In The Palgrave Handbook of Critical Thinking in Higher Education, ed. Martin Davies and Ronald Barnett, 491-508. New York: Palgrave. doi: 10.1057/9781137378057_29

Wise, David A. 1975. "Academic Achievement and Job Performance." American Economic Review 65: 350-366.

Wolanin, Thomas R. 2003. "The Student Credit Hour: An International Exploration." New Directions for Higher Education 2003(122): 99-117. doi: 10.1002/he.113

\section{Andrea J. Sell}

California Lutheran University, asell@callutheran.edu

Andrea Sell is the director of the Office of Undergraduate Research and Creative Scholarship at California Lutheran University, overseeing student research fellowships, coordinating workshops and events, and advocating for high-quality student research on campus. As an assistant professor in the Psychology Department, she teaches courses in cognition, memory, and physiological psychology, and her research focuses on the ways in which the human brain processes language, memory, and thought. 
Angela Naginey is the senior director of student success at California Lutheran University. She is responsible for leading and coordinating retention and student success efforts on campus and drives the initiatives and data collection related to success for first-year to doctoral students. She has worked at the university since 1997. She holds a bachelor's of arts degree in business administration, as well as a master's in counseling and guidance with an emphasis in college student personnel, from California Lutheran University.
Cathy Alexander Stanton, institutional research officer for California Lutheran University, is responsible for providing information that supports planning, policy formation, assessment, and decision making. Stanton began her career at the university in 1993 as an assistant to the vice president for academic affairs and transitioned to Institutional Research in 2000. She holds a bachelor's of science degree in business management, as well as a master's in public policy and administration, from California Lutheran University.

\title{
Did you know?
}

\section{The Council on Undergraduate Research has a Job and Opportunity Board available to members.}

\author{
Visit: community.cur.org
}

